\title{
Erratum to: Controlling $n$-Type Carrier Density from Er Doping of InGaAs with MBE Growth Temperature
}

\author{
PETER G. BURKE,${ }^{1,4}$ TREVOR E. BUEHL,${ }^{1}$ GILLES PERNOT,${ }^{3}$ HONG LU, ${ }^{1}$ \\ ALI SHAKOURI, ${ }^{3}$ CHRIS J. PALMSTROM, ${ }^{1,2}$ JOHN E. BOWERS, ${ }^{2}$ \\ and ARTHUR C. GOSSARD ${ }^{1,2}$ \\ 1.-Materials Department, University of California, Santa Barbara, CA 93106, USA. \\ 2.-Department of Electrical and Computer Engineering, University of California, Santa Barbara, \\ CA 93106, USA. 3.-Department of Electrical Engineering, University of California, Santa \\ Barbara, CA 93106, USA. 4.—e-mail: peterburke@umail.ucsb.edu
}

\section{Erratum to: Journal of ELECTRONIC MATERIALS}

Vol. 41, No. 5, 2012, pp. 948-953

DOI 10.1007/s11664-012-2050-5

Gilles Pernot's name was incorrect in the original article. It is correct as presented in this erratum. 